\title{
Orbitopterional Craniotomy Resection of Pediatric Suprasellar Craniopharyngioma
}

\author{
Devon LeFever $^{1}$ Chris Storey ${ }^{1}$ Bharat Guthikonda ${ }^{1}$ \\ ${ }^{1}$ Department of Neurosurgery, LSU Health Science Center, \\ Shreveport, Louisiana, United States \\ Address for correspondence Devon LeFever, MD, Department of \\ Neurosurgery, LSU Health Science Center, 1501 Kings Hwy, \\ Shreveport, LA 71103, United States (e-mail: DLeFev@lsuhsc.edu).
}

J Neurol Surg B 2018;79(suppl S3):S254-S255.

\begin{abstract}
The orbitopterional approach provides an excellent combination of basal access and suprasellar access. This approach also allows for less brain retraction when resecting larger suprasellar tumors that are more superiorly projecting due to a more frontal and inferior trajectory. In this operative video, the authors thoroughly detail an orbitopterional craniotomy utilizing a one-piece modified orbitozygomatic technique. This technique involves opening the craniotomy through a standard pterional incision. The craniotomy is performed using the standard three burr holes of a pterional approach; however, the osteotomy is extended anteriorly through the frontal process of the zygomatic bone as well as through the supraorbital rim. In this operative video atlas, the authors illustrate the operative anatomy, as well as surgical strategy and techniques to resect a large suprasellar craniopharyngioma in a 4-year-old male. Other reasonable approach options for a lesion of this size would include a standard pterional

\section{Keywords}

- craniopharyngioma

- orbitopterional

- pediatric neurosurgery

- suprasellar mass

- orbitozygomatic approach, a supraorbital approach, or expanded endoscopic transsphenoidal approach. The lesion was quite high and thus, the supraorbital approach may confine access to the superior portion of the tumor. While recognizing that some groups may have chosen the endoscopic expanded transsphenoidal approach for this lesion, the authors describe more confidence in achieving the goal of a safe and maximal resection with the orbitopterional approach.

The link to the video can be found at: https://youtu.be/eznsK16BzR8.
\end{abstract}

Conflict of Interest

None.

Funding

None.

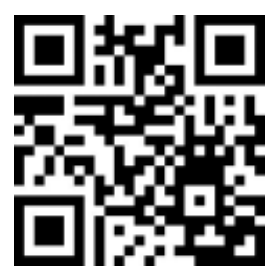

received

October 15, 2017

accepted

December 14, 2017

published online

February 26, 2018 www.thieme.com/skullbasevideos

www.thieme.com/jnlsbvideos

DOI https://doi.org/

10.1055/s-0038-1624589.

ISSN 2193-6331. (c) 2018 Georg Thieme Verlag KG Stuttgart · New York
License terms

(c) (i) $\ominus$ (5) 


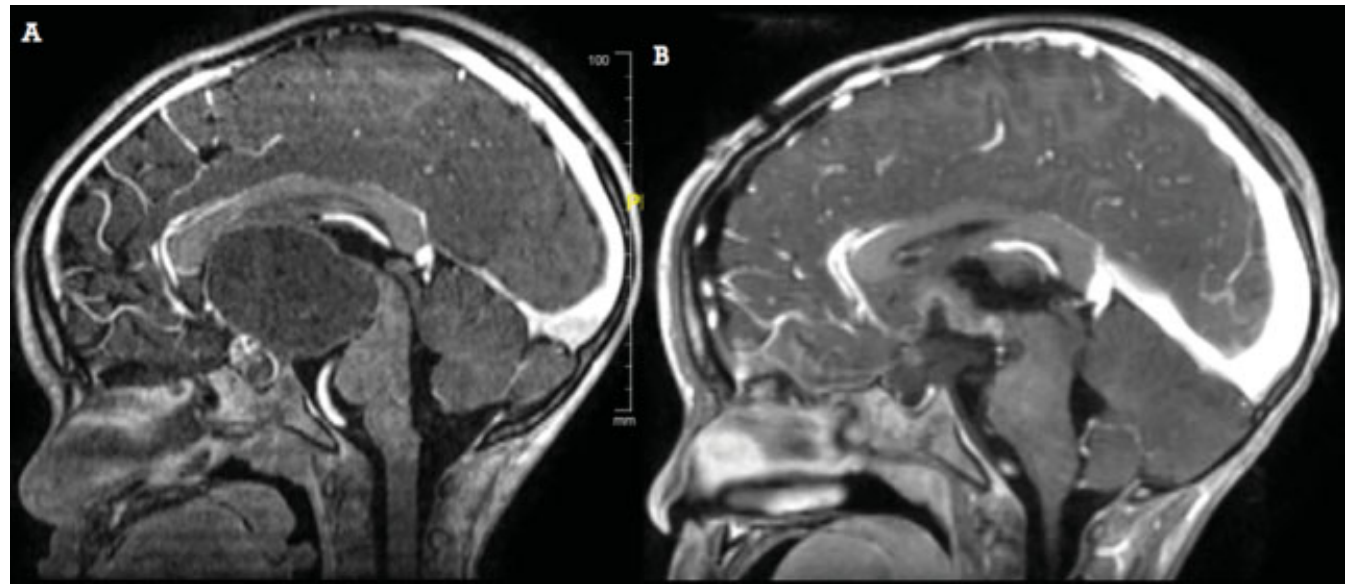

Fig. 1 Preoperative (A) and postoperative (B) sagittal T1 contrast-enhanced images demonstrating the resection of a larger suprasellar and superiorly projecting craniopharyngioma.

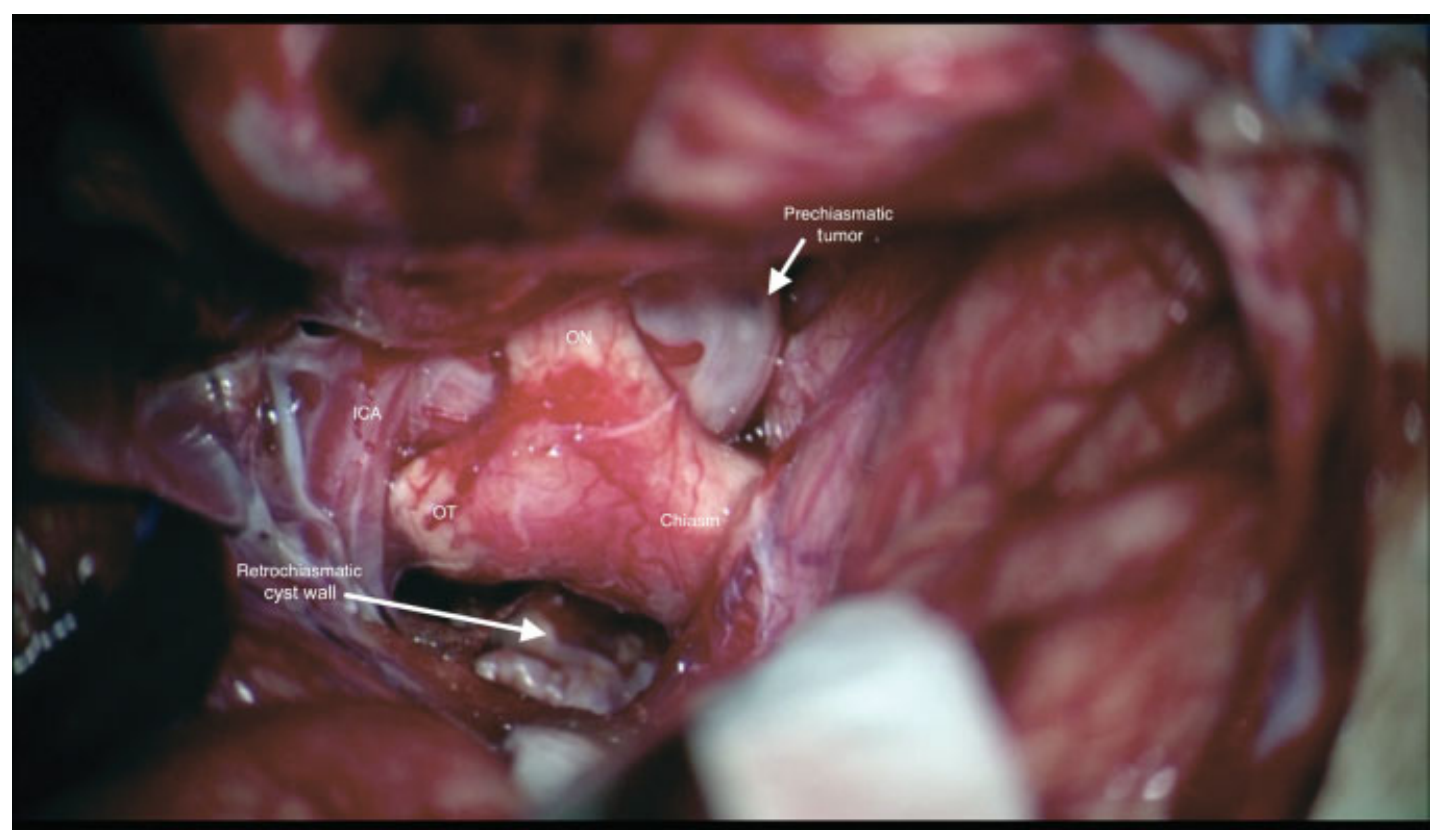

Fig. 2 Intraoperative still image demonstrating the left optic nerve (ON), optic tract (OT), optic chiasm, and internal carotid artery (ICA). The tumor wall is noted in the prechiasmatic corridor and a portion of the cyst wall is seen in the retrochiasmatic corridor. 